\title{
THE WAVES PELOS OLHOS DE BERNARD
}

\section{RESUMO}

$O$ presente trabalho objetiva pensar 0 processo de escrita pelo ponto de vista de Bernard ao esboçar um resumo da sua vida e da vida de seus amigos ao final do romance The Waves (1931) de Virginia Woolf. Sua escritura é problematizada ainda quando comparada à da mulher que escreve em Elvedon e aos poetas da década de 30, que Woolf alcunha os leaning tower poets. Pretende-se fazer uma releitura da importante contribuição aos estudos woolfianos desenvolvida por Jane Marcus em "Britannia Rules The Waves" (2004), que recuperou dados materiais que ajudam a compor a narrativa e a contextualizam histórica e biograficamente.

Palavras-chave: The Waves; Virginia Woolf; Escrita.
Patricia Marouvo Fagundes

Doutora em Letras na área de Literatura Comparada pela Universidade Federal do Rio de Janeiro. ${ }^{1}$ patriciamarouvo@yahoo.com.br

\begin{abstract}
This article aims to reflect on the process of writing through Bernard's perspective as he sketches a summary of his life and those of his friends at the end of Virginia Woolf's novel The Waves (1931). His writing is further problematized when compared to that of the woman writer in Elvedon and to those of the 1930s poets, who Woolf called the leaning tower poets. This article also carries out a critical reading of Jane Marcus's important contribution to Woolf studies entitled "Britannia Rules The Waves" (2004), in which she examines the materiality that helps to compose the narrative as well as to contextualize it historically and biographically.
\end{abstract}

Keywords: The Waves; Virginia Woolf; Writing. 
O romance The Waves (1931) de Virginia Woolf reúne cenas de um dia de verão, do nascer ao pôr do sol em uma praia inglesa, alternadamente conectadas a cenas das vidas de seis personagens principais, Bernard, Neville, Louis, Susan, Jinny e Rhoda, desde sua infância até sua velhice. Os interlúdios são narrados numa voz em terceira pessoa de tal modo removida da narrativa que parece descrever tanto os elementos humanos como os não-humanos na totalidade de captação do real. Intercaladas aos interlúdios, estão as nove diferentes seções do romance que apresentam as personagens diretamente, não havendo a intermediação de outrem, mas sim o conjunto de vozes que, uma seguida da outra, se interconectam ao retratarem determinada cena por diferentes perspectivas e se interpenetram na medida em que pontos retomados são assimilados de tal maneira que as falas das personagens podem ser facilmente confundidas. Ao final do romance, no entanto, Bernard se destaca ao assumir a tarefa de resumir o todo que haviam sido as vidas das seis personagens principais e também a vida de Percival, a sétima personagem silenciosa cuja força de atração sobre as outras as reúne em diversas passagens centrais da narrativa.

Conversando com um interlocutor em um restaurante, ele sente a liberdade de poder falar sem moralismos e sem necessariamente seguir uma linearidade teleológica nas histórias que se propõe narrar. Os dois parágrafos abaixo prefaciam a metodologia empregada e o que o próprio Bernard veio a construir no decorrer dos anos sobre o que entende por histórias, linguagem e escrita:

\footnotetext{
"Now to sum up", said Bernard. "Now to explain to you the meaning of my life. Since we do not know each other (though I met you once, I think, on board a ship going to Africa), we can talk freely. The illusion is upon me that something adheres for a moment, has roundness, weight, depth, is completed. This, for the moment, seems to be my life. If it were possible, I would hand it to you
} 
entire. I would break it off as one breaks off a bunch of grapes. I would say, 'Take it. This is my life'.

"But unfortunately, what I see (this globe, full of figures) you do not see. You see me, sitting at a table opposite you, a rather heavy, elderly man, grey at the temples. You see me take my napkin and unfold it. You see me pour myself out a glass of wine. And you see behind me the door opening, and people passing. But in order to make you understand, to give you my life, I must tell you a story - and there are so many, and so many - stories of childhood, stories of school, love, marriage, death, and so on; and none of them are true. Yet like children we tell each other stories, and to decorate them we make up these ridiculous, flamboyant, beautiful phrases. How tired I am of stories, how tired I am of phrases that come down beautifully with all their feet on the ground! Also, how I distrust neat designs of life that are drawn upon half-sheets of note-paper. I begin to long for some little language such as lovers use, broken words, inarticulate words. Like the shuffling of feet on the pavement. I begin to seek some design more in accordance with those moments of humiliation and triumph that come now and then undeniably. Lying in a ditch on a stormy day, when it has been raining, then enormous clouds come marching over the sky, tattered clouds, wisps of cloud. What delights me then is confusion, the height, the indifference and the fury. Great clouds always changing, and movement; something sulphurous and sinister, bowled up, helter-skelter; towering, trailing, broken off, lost, and I forgotten, minute, in a ditch. Of story, of design, I do not see a trace then. (WOOLF, 2015, 143)

A ilusão de que sua história de vida poderia alcançar o peso e a profundidade de uma completude que pudesse indicar o sentido da vida permanece uma ilusão como essa passagem muito bem ilustra. No primeiro parágrafo, a imagem utilizada para representar o todo dessas sete vidas - Bernard, Neville, Louis, Susan, Jinny, Rhoda e Percival - é a de um cacho de uvas. Se possível tomar essas vidas em suas mãos, se possível dar um sentido completo e finito a algo inacabado e ainda posto em desdobramento, cada vida e cada história teria a corporeidade de cada uva neste cacho de sete. A imagem, entretanto, revelando o potencial de sentidos múltiplos a serem construídos naquele mundo, naquele pequeno e frágil corpo finito de cada uva, parece ser impossível pela linguagem linear, impossível relatar a totalidade de um emaranhado de tempos e dimensões intercruzados pela percepção e pelo afeto que tomam Bernard, como narrador e como personagem, e cada um de seus amigos. Essa narrativa como impossibilidade de se fazer objeto que poderia ser passada das mãos do sujeito, que aqui 
fala, para outro, que aqui ouve ou lê, aponta para uma compreensão outra do que na obra woolfiana poderíamos entender por escrita.

Se essas vidas, esses mundos povoados por experienciações singulares não podem ser agarrados, já que nenhuma dessas histórias seria verdadeira, pois elas somente dão a falsa impressão de um todo finito e acabado, ao leitor resta aceitar que a língua falha por não poder veicular uma mensagem sólida e eficaz, mas tão somente palavras quebradas, palavras inarticuladas. Essas palavras poderiam ser comparadas ao arrastar de pés na calçada, cujos passos desencontrados não seguem uma direção única, que não mais tentam renunciar ou disfarçar a transitoriedade das relações e situações e sentidos que, de um momento para o outro, podem ser acessados por vias novas e encaminhar reflexões que ponham por terra quaisquer certezas que se queiram absolutas. A realidade não se revelando por completo, o escritor se atém ao que pode ser construído a partir do dito e trabalhar o potencial do que se retrai e foge à língua, procurando criar conexões novas e originais, não pelo simples desejo estilístico ou egoístico, mas sim para desdobrar pensamento e ensejar outras vias de compreensão e performance.

Talvez a cena imaginada no segundo parágrafo possa melhor encapsular esses contrastes, onde Bernard vê a si mesmo como mero corpo jogado numa vala em uma manhã tempestuosa. A chuva caindo, nuvens enormes passam por ele lá no céu, provocando um misto de sentimentos de confusão, vertigem, indiferença e fúria, pois as forças de vida e morte passando na frente de seus olhos, o fazem enxergar também as forças que o movem cotidianamente, mas que nesse momento tão singular o prostram frente à impossibilidade de verbalizar a percepção de que, a despersonalização sendo alcançada num instante fugaz, seu corpo parece se integrar aos elementos. Isso, porém não pode ser totalmente efetivado por ainda respirar, perceber e pensar, sua 
corporeidade ainda o prendendo a uma humanidade da qual Woolf não parece querer ou poder abrir mão de todo, ainda que a magnanimidade da condição nos apequene e paralise frente ao movimento de subidas e descidas, ritmos que escapam a razão e vontade humanas em sua finitude. Tais momentos parecem de tal modo dissolver a arquitetura das histórias que Bernard sempre idealizou e contou a seus amigos no decorrer de sua vida que somente agora, chegando à velhice e tentando resumir o todo de suas vidas, que a forma parece ceder e não mais sustentar sua fala que, num bravejar último, vocifera contra a morte, mas por ela é assimilada. O silêncio acaba sendo a resposta derradeira para as questões sobre a linguagem e a forma no plano da imanência postas no romance, a onda engolindo todas as personagens num movimento final.

É importante lembrar aqui também a mulher que Bernard e Susan podiam avistar ao longe na casa em Elvedon:

Down below, through the depths of the leaves, the gardeners swept the lawns with great brooms. The lady sat writing. Transfixed, stopped dead, I thought, "I cannot interfere with a single stroke of those brooms. They sweep and they sweep. Nor with the fixity of that woman writing. It is strange that one cannot stop gardeners sweeping nor dislodge a woman. There they have remained all my life. It is as if one had woken in Stonehenge surrounded by a circle of great stones, these enemies, these presences. (WOOLF, 2015, p. 144-145)

Essa mulher escrevendo já incorporava ainda no início do romance a sentença que, resistindo frente às forças da sociedade patriarcal, performava a alteridade que trazia consigo e, escrevendo, pensava e produzia dentro de uma comunidade que pelas bordas poderia criticamente avaliar os impasses de seu tempo. Esta seria uma sociedade de outsiders, que quebrava o silêncio de séculos de subjugação feminina ${ }^{2}$ a fim de adentrar o palco de ações dessa mesma sociedade agora com uma voz própria, que não buscasse somente o grito da raiva, que muito facilmente poderia ser desqualificado sob o 
mote de histeria, mas buscasse também desarticular a sentença masculina ${ }^{3}$ pela ironia e pela multivocalidade que o texto woolfiano ajuda a ilustrar tão exemplarmente. Se essa mulher escritora já aparecia no início do romance, no decorrer da narrativa ela volta para marcar principalmente o resumo final de Bernard, simbolicamente reunindo uma força tão milenar quanto Stonehenge na história da Inglaterra, como se, como as pedras erigidas, também a mulher houvesse protagonizado em seus empenhos domésticos, criando filhos e filhas, ou melhor contribuindo diretamente para a manutenção da espécie e a ascensão do império britânico sem, no entanto, ter seus trabalhos valorizados e reconhecidos materialmente até bem recentemente - quando, através de atos parlamentares, em 1918 as mulheres conquistaram o direito de voto e em 1919 a elas foi permitido exercer um trabalho remunerado fora de casa, como bem aponta a pesquisa feita em Three Guineas (1938). A escritora a que Bernard se refere dá um passo além ao redimensionar a contribuição das mulheres também pela escrita, marcando sua infância e recontornando a possível trajetória que sua leitura de mundo poderia ter seguido senão por esse encontro inesperado.

Além dessa mulher escritora, entretanto, também figuram os jardineiros na passagem acima, entreabrindo a realidade da classe trabalhadora, um mundo somente sugerido na obra woolfiana, mas, de fato, pouco explorado por Woolf senão de passagem, alertando para a necessidade de pensar também sua exclusão dentro do sistema. Em "Britannia Rules The Waves" (2004), Jane Marcus realiza um importante trabalho de resgate de uma possível leitura mais material e política da obra ${ }^{4}$, algo que por muito tempo havia sido desconsiderado, relegando o romance a discussões acerca da técnica e do experimentalismo com gêneros literários, o que, de fato, mostra como a forma é inegavelmente brilhante e uma questão central no texto woolfiano. Jane Marcus 
(2004) alerta para a representação das diferentes classes na passagem acima, em que uma lady, e não simplesmente uma woman, ou melhor uma figura feminina aristocrática em uma casa de campo grandiosa, tem o privilégio de pensar e escrever somente pelos esforços necessários para o bom funcionamento social, assegurado pela classe trabalhadora que lhe serve. Esse duplo que recorre a Bernard do início ao fim do romance, Marcus (2004) argumenta, atua como uma das instâncias de ironia do texto woolfiano que, em The Waves, serve para desarticular a ideologia de classe, império e gênero de sua época.

Posta em xeque, para Jane Marcus (2004), também está a autoridade do próprio Bernard como escritor, visto que sua fala ao final do romance poderia ser entendida como uma paródia do próprio conceito de autoria, o que alargaria os limites que as classificações mais didáticas tentam localizar Woolf como escritora modernista ${ }^{5}$, já que seu texto possui diversas das características que mais tarde seriam agrupadas no intuito de definir o pós-modernismo, de acordo com as definições propostas por Linda Hutcheon $^{6}$, por exemplo. Assim, Marcus (2004) elenca diversas marcas que singularizam a obra referida ao desafiar a classificação tradicional que separa o modernismo do pósmodernismo, dado que em The Waves podem ser presenciados: o enfraquecimento da fé humanista no sujeito coerente; a dúvida sobre a integridade do artista; o uso da paródia e da ironia, que debocham da cumplicidade entre o herói e o poeta na criação de um sujeito nacional coletivo; a intertextualidade do romance com a poesia romântica; o questionamento da ansiedade do homem branco em expressar sua identidade como experiência universal; a criação de "the quantum self" ao incorporar novas teorias da física, fazendo suas personagens se desdobrarem uma nas outras; a criação, também, de "quantum text", apresentando a relatividade do tempo na estrutura dupla entre o passar 
de um dia nos interlúdios, simultâneo ao atravessamento das experiências das personagens nos oito episódios do romance.

O poder de síntese de Jane Marcus revigora com grande potência seu texto, em especial pelo alto teor criativo e a seriedade com que relê The Waves, alertando para o fato de essa obra ser altamente crítica dos discursos discriminatórios quanto a gênero, raça e classe social, algo que até o início dos anos 2000 havia sido pouco explorado. Vale perguntar, no entanto, se a interpretação que Marcus faz acerca da personagem principal e de seu resumo ao final do romance não reduziria os desdobramentos da fala de Bernard e a própria dinâmica do processo de escrita a leituras que reduzam a potência do texto woolfiano às forças materiais apenas. Ao atuar somente no campo biopolítico, a releitura de Marcus desconsidera o vigor do plano de imanência ${ }^{7}$, sempre apresentado na sinuosidade do movimento de sentença woolfiana através dos sons e do ritmo do texto e das imagens que atuam como complexo metafórico, ressurgindo dos recessos das palavras escolhidas no texto para também deixar falar o silêncio do que se resguarda. Em "Britannia Rules The Waves", Jane Marcus afirma que Bernard, enquanto o artista, estaria "stealing the subjectivities of his friends, their marginalized voices and silences, their images of disaster and the meaninglessness of the universe" (MARCUS, 2004, p. 70). Isso porque, encarnando a voz do autor branco, agente e herdeiro direto da civilização ocidental, Bernard absorveria a fala de seus companheiros marginalizados na sua produção de modo a fazer da alteridade do olhar e, por extensão do ego alheio, personagens de sua história, meros componentes literários para atingir seus objetivos em sua produção ficcional.

Deve-se levar em consideração, entretanto, que o resumo que se torna o empenho improvisado de Bernard ao final do romance já se assume uma escrita em 
primeira pessoa, que se apresenta como possibilidade após anos de convívio e impactos com seus amigos na maneira como a presença deles ainda na ausência, seja pelo suicídio de Rhoda ou pela morte prematura de Percival, o envolvem no quebrar das ondas de influência e experiência nas quais sua vida se desdobra. Sua escrita autobiográfica claramente parte dos pressupostos de que, como herdeiro direto do império britânico, ou ainda, como um homem branco de classe média alta que teve acesso às melhores escolas públicas e, posteriormente, universidades da Inglaterra, seu eye/l é diretamente influenciado pelos privilégios que sua posição Ihe confere. Ela é, de fato, marcada pela ideologia imperialista, racista, classista e sexista que seria natural esperar de sua época, como Jane Marcus (2004) bem aponta ao relacionar as personagens aos membros do grupo de Bloomsbury e outros intelectuais dos meios pelos quais Virginia Woolf costumava transitar.

Bernard é comparado, mais especificamente, a Desdmond MacCarthy, com quem Woolf já havia discutido furiosamente sobre gênero e escrita, tendo MacCarthy afirmado que as mulheres seriam inferiores aos homens intelectualmente, pois o desejo que elas tinham em serem dominadas já seria prova material de uma suposta inferioridade. Ainda que tenha se inspirado em homens como os Cambridge Apostles para criar suas personagens, Woolf redimensiona suas crenças e qualidades de tal modo que de sua escrita irrompem dubiedades e incertezas, que poderiam ser entendidas como deslocamento de supostas posições tomadas do início ao fim do romance, ainda mais considerando a fluidez com que a singularidade se metamorfoseia no outro, por forças externas e internas, que, no final das contas, se mostram incategorizáveis por si só.

Além disso, como leitores, ainda temos acesso à diferença anunciada nas vozes das outras personagens no decorrer do romance, sem sequer que as mesmas fossem 
intermedidas por um narrador, o que mostra o grau de liberdade para a expressão de uma fala para a qual não haveria um interlocutor imediato, como o ouvinte a quem Bernard confidencia sua história de vida ao final da obra. Assim como Bernard, as outras personagens parecem escapar a papéis previamente articulados pelas instituições do seu tempo, agindo, sim, como corpos imperiais em certas instâncias, mas também fugindo ao desempenho deles em momentos do ser, em que cada uma delas parece mais autenticamente desarticular categorias às quais as mulheres britânicas deveriam pertencer, como "Rhoda the hysteric, Ginny the prostitute, and Susan the mother" (MARCUS, 2004, p. 70). É interessante, porém questionável, como a leitura de Jane Marcus parece compactuar o discurso imperial de Bernard com a atuação de brutalidade física e verbal de Percival, de modo a sequestrar as outras vozes e experiências que também povoam o texto woolfiano, silenciando-as através de uma interpretação que evidencia a arrogância classista e a intolerância racial de ambos.

Ao atribuir a Bernard o título de "um poeta de sua geração" (MARCUS, 2004, 71), poderíamos inferir que talvez Bernard pertencesse à geração de 30, dentre os quais figuram Day Lewis, Auden Spender, Isherwood e Louis MacNeice, por exemplo. No ensaio "The Leaning Tower" (1940), Woolf discorre sobre as condições de possibilidade de se produzir poesia na década de 30 , agrupando os poetas da época sob a alcunha de leaning tower poets. Nesse período entre guerras, esses poetas advindos da classe média alta inglesa ainda escreviam do alto de sua torre, da qual podiam avistar as outras classes, suas subalternas, nas quais personagens podiam ser inspirados dada a tradição literária inglesa, em especial na ficção, de trabalhar com tipos sociais, desde os mais caricatos aos mais multifacetados. Woolf observa, no entanto, que, após a Primeira Guerra Mundial, as estruturas sociais e as instituições sobre as quais os valores imperiais se balizavam 
sofreram um choque profundo de tal modo que a torre de estuque teve seu centro de gravidade abalado, levemente curvando-se, a ponto de dali os poetas da década de 30 só enxergarem o mundo à sua volta também enviesado, decentralizado. Sua poesia, altamente autobiográfica volta-se para si mesma, encontrando na burguesia a que pertence o bode expiatório para os problemas de seu tempo, sem, entretanto, entrever possíveis soluções. Nesse sentido, Woolf indagava:

\begin{abstract}
When they looked at human life what did they see? Everywhere change; everywhere revolution. In Germany, in Russia, in Italy, in Spain, all the old hedges were being rooted up; all the old towers were being thrown to the ground. Other hedges were being planted; other towers were being raised. There was communism in one country; in another fascism. The whole of civilisation, of society, was changing. There was, it is true, neither war nor revolution in England itself. All those writers had time to write many books before 1939. But even in England towers that were built of gold and stucco were no longer steady towers. They were leaning towers. (WOOLF, 1975, p. 139-140)
\end{abstract}

Porque a torre de onde miravam o mundo ao seu redor estava levemente inclinada, esses escritores, graças à sua classe social e à sua educação de alto nível e cara, tornavam-se muito conscientes do fato de que estavam em uma torre. Essa leve inclinação produzia um certo desconforto, acompanhado de um sentimento de pena da própria condição em que se encontravam, a qual se transformava em seguida em raiva contra a sociedade que criou as estruturas que os amparavam, que, nesse contexto, se tornava o bode expiatório desse sentimento mimético externalizado. Assim sendo, sua produção se caracteriza pela brilhante investigação egoística de sua trajetória privilegiada, dos estudos acadêmicos ao mercado de trabalho, pois seria impossível abrir mão de todos os privilégios que a vida Ihes havia prometido desde berço, algo que até mesmo arriscaria suas carreiras literárias, e, como resultado, sua poesia revela a discórdia, o amargor, a confusão e a concessão que os perturbavam, sem, ainda assim, 
atacar de frente a fim de desmantelar as instituições com as quais lucravam. Sua hipocrisia advinha de julgar e pregar, através de seus escritos, mas não de suas ações, a favor de uma sociedade em que todos fossem livres e iguais, algo que, Woolf (1975) sugere, explica o tom pedagógico e didático de alto-falantes que dominam sua poesia. Ela conclui que aquilo que esses poetas mais anseiam é "to be closer to their kind, to write the common speech of their kind, to share the emotions of their kind, no longer to be isolated and exalted in solitary state upon their tower, but to be down on the ground with the mass of human kind" (WOOLF, 1975, p. 147).

Bernard, de fato, partilha de muitas das características desse grupo de poetas da década de 30. Contudo, certos momentos parecem escapar à sua compreensão, e, nessa fuga ao recorte que Woolf traçou para alcunhar os leaning tower poets, Bernard aponta para os limites do seu pensamento no momento de contato com o outro, cujas linhas de fuga parecem indicar, já desde a infância quando retomada pelo olhar da velhice, possibilidades outras de ser no mundo, como a dos jardineiros e a da dama escrevendo ao longe. O excerto abaixo remonta ao momento em que Bernard consola Susan quando esta testemunha o beijo roubado que Jinny dá em Louis:

That I observed even in the midst of my anguish when, twisting her pockethandkerchief, Susan cried, "I love, I hate". "A worthless servant", I observed, "laughs in the attic", and that little piece of dramatization shows how incompletely we are merged in our own experiences. On the outskirts of every agony sits some observant fellow who points; who whispers as he whispered to me that summer morning in the house where the corn comes up to the window, "The willow grows on the turf by the river. The gardeners sweep with great brooms and the lady sits writing". Thus he directed me to that which is beyond and outside our own predicament; to that which is symbolic, and thus perhaps permanent, if there is any permanence in our sleeping and eating, breathing so animal, so spiritual and tumultuous lives. (WOOLF, 2015, p. 149) 
A consciência de classe de Bernard não parece cair numa culpa ensimesmada que buscaria um bode expiatório a fim de superficialmente aparentar solucionar o problema em questão. À margem de toda experienciação, vivida ou rememorada, está a alteridade que o outro, como corpo individual ou coletivo, apresenta como algo que surge para além de nosso horizonte de compreensão, ainda que não necessariamente de sensibilização. Ao exclamar que um criado inútil ria no sótão, Bernard vocifera contra qualquer forma de diminuição da dor que sente, espelhada na dor de sua amiga Susan, quando, pela primeira vez no romance, ela pode experimentar as dores que o ciúme causa naquele que é excluído, tendo seu objeto de desejo renegado. O que é, nas palavras de Bernard, simbólica nessa cena que retorna é a presença da alteridade incorporada nas figuras dos jardineiros e da mulher escritora, revelando em uma instância uma tensão na disputa de classes sociais, uma delas sendo relegada ao trabalho braçal enquanto à outra cabia o trabalho intelectual dadas as condições materiais que privilegiavam e possibilitavam ler, pensar e escrever como formas de exercer diferença pela performance, sem, no entanto, compactuar com o projeto de perpetuação da exclusão, entendido como constitutivo da sentença masculina para Woolf.

Se aqui a dama sentada escreve, isso não necessariamente indica uma entrada dessa outsider no clube de homens, professores universitários, bispos e ditadores, todos coniventes com o massacre de tudo que não sucumbisse aos mandos do império do mesmo. Como outsiders, essas mulheres partilham da escrita como plataforma para alcançar outros modos de compreensão e existência juntamente com outros outsiders, seja no nível de exclusão de gênero, social ou racial - todas essas questões admitidas por Woolf ainda que trabalhadas marginalmente por ela mesma não poder ocupar esse lugar 
último que é do outro, o da classe trabalhadora e o dos colonizados, ela não tendo, assim, esse lugar de fala.

Ainda em "The Leaning Tower", porém, ela já questionava se talvez num futuro não muito distante, a redistribuição de renda ocasionada com a taxação das grandes fortunas na Inglaterra durante a Segunda Guerra Mundial não levaria à maior difusão de conhecimento, as crianças pertencendo todas ao sistema educacional universal, e isso não levaria a um futuro em que as diferenças entre as classes não fossem tão alarmantes e injustas, perpetuando a exclusão da grande maioria. A leitura, Woolf argumenta, permitirá o desenvolvimento de um letramento crítico das massas num mundo em que "in future it is we who shall decide whom to send to public schools and universities; how they shall be taught; and whether what they write justifies their exemption from other work" (WOOLF, 1975, p. 153). Nesta passagem, é enfatizada a extrema importância de permitir que a sensibilidade natural e a dedicação contínua revelem quais escritores podem alavancar a literatura inglesa para além do mercado de massas, impulsionando o pensamento e a arte como um projeto nacional que abraçaria todas as camadas sociais, uma vez que a todas seriam dadas as condições materiais iniciais para que tal empreendimento pudesse vir à tona e gradativamente a produção intelectual se fortaleceria e permitiria aos verdadeiros escritores o tempo e as condições financeiras para poderem realizar seu ofício plenamente, não precisando ter outra função profissional e social que não a de difundir uma literatura para além das classes.

Encerro este artigo com as palavras finais de Woolf em "The Leaning Tower", passagem em que ela convida seus leitores e demais outsiders a também obliterarem quaisquer linhas e regras que estagnem esse movimento inaugural, advertindo que: 
Literature is no one's private ground; literature is common ground. It is not cut up into nations; there are no wars there. Let us trespass freely and fearlessly and find our own way for ourselves. It is thus that English literature will survive this war and cross the gulf - if commoners and outsiders like ourselves make that country our own country, if we teach ourselves how to read and to write, how to preserve and how to create. (WOOLF, 1975, p. 154)

\section{Referências}

MARCUS, Jane. "Britannia Rules The Waves". In: Hearts of Darkness - White Women Write Race. New Jersey: Rutgers University Press, 2004, p. 59-85.

WOOLF, Virginia. The Waves. London: Oxford University Press, 2015. . Three Guineas. New York: Harcourt Inc, 1966.

. "The Leaning Tower". In: The Moment and Other Essays. New York: Harcourt Brace, 1975, p. 128-154.

Recebido em 29 de maio de 2019.

Aceito em 11 de novembro de 2019.

\footnotetext{
${ }^{1}$ Doutora em Letras na área de Literatura Comparada (2019) pela Universidade Federal do Rio de Janeiro. Possui mestrado em Letras na área de Poética (2012) e graduação em Letras: Português/Inglês (2009) pela Universidade Federal do Rio de Janeiro. Trabalha como professora adjunta no curso de Letras - Língua Inglesa e Respectivas Literaturas da Universidade Federal do Acre. Atualmente coordena o projeto de pesquisa "Por uma filosofia woolfiana: repercussões de The Waves na contemporaneidade".

2 Para uma leitura feminista obra woolfiana, conferir GOLDMAN, Jane. The Feminist Aesthetics of Virginia Woolf-Modernism, Post-Modernism and the Politics of the Visual. New York: Cambridge University Press, 2001.

${ }^{3}$ Cf. A Room of One's Own (1928) para um melhor entendimento do que Woolf entende por sentença feminina e sentença masculina.

${ }^{4}$ Para uma leitura materialista da vida e da obra de Virginia Woolf, conferir ZWERDLING, Alex. Virginia Woolf and the Real World. Los Angeles: University of California Press, 1986.

5 Para uma leitura crítica do conceito de Modernismo, conferir GOLDMAN, Jane. Modernism, 1910-1945, Image to Apocalypse. Basingstoke: Palgrave MacMillan, 2004.

${ }^{6}$ Cf. HUTCHEON, Linda. Poética do pós-modernismo: história, teoria e ficção. Rio de Janeiro: Imago Ed., 1991.
} 
${ }^{7}$ Cf. BRAIDOTTI, Rosi. Nomadic Theory, The Portable Rosi Braidotti. New York: Columbia University Press, 2011. 